\title{
MMS19 localizes to mitochondria and protects the mitochondrial genome from oxidative damage
}

\begin{tabular}{|c|c|}
\hline Journal: & Biochemistry and Cell Biology \\
\hline Manuscript ID & bcb-2017-0149.R1 \\
\hline Manuscript Type: & Article \\
\hline Date Submitted by the Author: & 09-Aug-2017 \\
\hline Complete List of Authors: & $\begin{array}{l}\text { Wu, Rui; Beijing Institute of Genomics Chinese Academy of Sciences, Key } \\
\text { Laboratory of Genomic and Precision Medicine, China Gastrointestinal } \\
\text { Cancer Research Center; University of the Chinese Academy of Sciences } \\
\text { Tan, Qunsong; Beijing Institute of Genomics Chinese Academy of Sciences, } \\
\text { Key Laboratory of Genomic and Precision Medicine; University of the } \\
\text { Chinese Academy of Sciences } \\
\text { Niu, Kaifeng; Beijing Institute of Genomics Chinese Academy of Sciences, } \\
\text { Key Laboratory of Genomic and Precision Medicine, China Gastrointestinal } \\
\text { Cancer Research Center; University of the Chinese Academy of Sciences } \\
\text { Zhu, Yuqi; Beijing Institute of Genomics Chinese Academy of Sciences, Key } \\
\text { Laboratory of Genomic and Precision Medicine, China Gastrointestinal } \\
\text { Cancer Research Center; University of the Chinese Academy of Sciences } \\
\text { Wei, Di; Beijing Institute of Genomics Chinese Academy of Sciences, Key } \\
\text { Laboratory of Genomic and Precision Medicine, China Gastrointestinal } \\
\text { Cancer Research Center } \\
\text { Zhao, Yongliang; Beijing Institute of Genomics Chinese Academy of } \\
\text { Sciences, Key Laboratory of Genomic and Precision Medicine; University of } \\
\text { the Chinese Academy of Sciences } \\
\text { Fang, Hongbo; Beijing Institute of Genomics Chinese Academy of Sciences, } \\
\text { Key Laboratory of Genomic and Precision Medicine, China Gastrointestinal } \\
\text { Cancer Research Center }\end{array}$ \\
\hline $\begin{array}{r}\text { Is the invited manuscript for } \\
\text { consideration in a Special } \\
\text { Issue? : }\end{array}$ & N/A \\
\hline Keyword: & MMS19, Mitochondria, ROS, oxidative stress, ANT2 \\
\hline
\end{tabular}


MMS19 localizes to mitochondria and protects the mitochondrial genome from oxidative damage

Rui Wua,b,1, Qunsong Tanna,b,1, Kaifeng Niua,b, Yuqi Zhua,b, Di Weia,b, Yongliang Zhao ${ }^{a, b}$, Hongbo Fang ${ }^{a, b},{ }^{*}$

aKey Laboratory of Genomic and Precision Medicine, Beijing Institute of Genomics, Chinese Academy of Sciences, Beijing 100101, China bUniversity of Chinese Academy of Sciences, Beijing 100049, China *Corresponding authors. Address: NO.1 Beichen West Road, Chaoyang District, Beijing 100101, China. Phone : 8610-84097648, Fax: $+86-10-84097648$.

E-mail address: Fanghb@big.ac.cn (H. Fang).

${ }^{1}$ Rui Wu and Qunsong Tan contributed equally to this paper. 


\section{ABSTRACT}

MMS19 localizes to cytoplasmic and nuclear compartments involving in transcription and nucleotide excision repair (NER). However, whether or not MMS19 localizes to mitochondria where it plays a role in maintaining mitochondrial genome stability remains elusive. In this study, we provide the first evidence that MMS19 is localized in the inner membrane of mitochondria and participates in mtDNA oxidative damage repair. MMS19 knockdown led to mitochondrial dysfunctions including decreased mtDNA copy number, diminished mtDNA repair capacity and elevated level of mtDNA common deletion after oxidative stress. Immunoprecipitation-mass spectrometry analysis identified that MMS19 interacts with ANT2, a mitochondrial ATP metabolism-associated protein. ANT2 knockdown also resulted in a decreased mtDNA repair capacity post oxidative damage. Our findings suggest that MMS19 plays an essential role in maintaining mitochondrial genome stability. 
Key words: MMS19, Mitochondria, ANT2, ROS, oxidative stress 


\section{Introduction}

Methyl methanesulfonate sensitivity gene 19 (MMS19) is a highly conserved HEAT repeat protein that was first identified in Saccharomyces cerevisiae as being required for the removal of ultraviolet radiation (UV)induced pyrimidine dimers (Gari et al. 2012). Like TFIIH components, MMS19 appears to be involved in both nucleotide excision repair( NER ) and RNA polymerase II transcription (Lombaerts et al. 1997). Human MMS19 physically interacts with the XPB (Ss/2 homologue) and XPD (Rad3 homologue) subunits of TFIIH (Ito et al. 2010), and is assumed to be an upstream regulator of TFIIH activity, though the biological significance of these interactions remains unclear. MMS19 exerts its function in NER and transcription by interacting with the XPB and XPD helicases (Kou et al. 2008; Seroz et al. 2000). MMS19 protein contains three conserved regions, including domains $A$ and $B$ and a HEAT repeat domain $C$, and has been postulated to modulate the balance between transcription and DNA repair (Queimado et al. 2001). Mutants in eukaryotic MMS19 show a variety of phenotypes, including defects in 
methionine synthesis, sensitivity to genotoxic stress induced by MMS (methyl methanesulfonate), and the presence of extended telomeres (Stehling et al. 2012).

Mitochondria are known as the 'power house' of the cell where ATP is generated by electron transport and oxidative phosphorylation across inner mitochondrial membrane, along which reactive oxygen species (ROS) as the by-product are formed continuously during normal cellular metabolism. ROS can result in multiple DNA lesions, such as abasic sites, oxidized DNA bases, and single- or double-strand breaks (Maynard et al. 2009). Since mitochondria DNA is lack of protective histones and is constantly exposed to free radical species, mtDNA is more sensitive than nuclear DNA in response to oxidative stress with persistent mtDNA damage and loss of mitochondrial function (Bohr 2002; Klaunig et al. 2011). Both mismatch repair (MMR) and base excision repair (BER) pathways are found in the nucleus and mitochondria. Although UV-induced nucleotide excision repair (NER) is observed to be defective in mitochondria, key nucleotide excision repair factor such as 
CS proteins (CSA and CSB), Rad23a, and XPD have been localized in mitochondria (Liu et al. 2015; Melis et al. 2013). In addition, RecQL4, one of the five human RecQ helicases, is revealed to be located in mitochondria, and plays regulatory role in the maintenance of mitochondrial genome stability (Chi et al. 2012).

This is the first time we have identified that MMS19 is localized to the mitochondrial fractions and mtDNA deletion has been increased in MMS19-knockdown cells. Strikingly, capacity for oxidative mtDNA damage repair was markedly reduced in MMS19-knockdown cells. Similar to the reduced mtDNA repair capacity in MMS19-knockdown cells, oxidative mitochondrial DNA damage repair capacity in U2OS cells was also significantly changed after ANT2 knockdown. The siRNA-mediated knockdown of MMS19 or ANT2 led to mitochondrial dysfunction, which illustrated the significance of both MMS19 and ANT2 proteins for the mtDNA repair. Co-immunoprecipitation results revealed that SSBP1, a protein involved in mitochondrial DNA replication and molecular chaperone HSP70 directly interacted with MMS19, suggesting 
that a potential mechanism in which MMS19 enters mitochondria by interacting with molecular chaperone HSP70. Furthermore, Our findings show that MMS19 plays an important role in the maintenance of mitochondrial genomic DNA stability through its interaction with mitochondrial proteins.

\section{Materials and methods}

\subsection{Cell culture and transfections}

U2OS, 293F, HEK293 and HeLa S3 were incubated in Dulbecco's modified Eagle' s medium (DMEM) supplemented with $10 \%(\mathrm{v} / \mathrm{v})$ fetal bovine serum (FBS, Hyclone) at $37^{\circ} \mathrm{C}$ in humidified incubator with $5 \% \mathrm{CO}_{2}$. U2OS cells were treated with $1 \mathrm{mM} \mathrm{H} \mathrm{H}_{2}$ for 1 hour at $37^{\circ} \mathrm{C}$ in FBS-free medium. The siRNA for MMS19: GCAAUGUACUGCCUUUACUTT, siRNA for ANT2: GAUCACUGCAGAUAAGCAATT and siRNA control: UUCUCCGAACGUGUCACGUTT were synthesized by GenePharma (China). U2OS cells were transfected with RFect siRNA transfection reagent 
(BIO-TRANS, China). pcDNA3.0/HA-MMS19 was used to generate HeLa

S3 stable cell lines with $600 \mu \mathrm{g} / \mathrm{ml}$ Hygromycin B.

\subsection{Alkali extraction of mitochondria}

mitochondria were treated with $0.1 \mathrm{M} \mathrm{Na}_{2} \mathrm{CO}_{3}(\mathrm{pH} 11.5)$, and then

centrifuged at $16,000 \mathrm{~g}$. Supernatants $(\mathrm{S})$ were retained. The pellet $(\mathrm{P})$ were washed once and then suspended in an suspension medium (Liu et al. 2015).

\subsection{Long-range quantitative $P C R(Q P C R)$ assay}

Total cellular DNA was extracted using Qiagen genomic DNA isolation kit. A novel quantitative PCR assay was used to measure $\mathrm{H}_{2} \mathrm{O}_{2}$-induced DNA damage and repair in a $13.5-\mathrm{kb}$ fragment up stream of the nuclear $\beta$-globin gene and a $16.2-\mathrm{kb}$ fragment from the $\begin{array}{lll}\text { mitochondrial } & \text { genome. } & \text { These }\end{array}$

5' -TAGAGGGACAAGTGGCGTTC-3' , 5' -CGCTGAGCCAGTCAGTGT-3'

5' -CACCCAAGAACAGGGTTTGT-3' ， 5' -TGGCCATGGGTATGTTGTTAA-3' 
were used for relative quantitation with the Bio-Rad CFX96 Real-Time PCR Detection Systems. The following primers $\beta$-globin gene: 5' -CGAGTAAGAGACCATTGTGGCAG-3' and 5' -GCACTGGCTTAGGAGTTGGACT-3' ; mtDNA gene: 5' -TGAGGCCAAATATCATTCTGAGGGGC-3' and 5' -TTTCATCATGCGGAGATGTTGGATGG-3' were used for PCR. The PCR was done as (Liu et al. 2015).

\subsection{Measurement of common deletion}

Cells were grown in serum free medium and treated with $0.5 \mathrm{mM}$ $\mathrm{H}_{2} \mathrm{O}_{2}$ with or without 5, $000 \mathrm{U} / \mathrm{mL}$ Catalase, then the genomic DNA was extracted. Measurement of common deletion (CD) was done by QPCR using the primers: $5^{\prime}$-ACCCCCATACTCCTTACACTATTCC-3' and 5' -AAGGTATTCCTGCTAATGCTAGGCT-3' . An 83 bp PCR fragment served as a standard (Kamenisch et al. 2010). 


\subsection{Isolation of mitochondria, Co-immunoprecipitation assay and} protein identification by mass spectrometry

The large-scale mitochondrial fraction was performed as previously described (Graham 2001). HA-MMS19 stable expression The mitochondrial fraction in HeLa cells were collected and suspended in lysis buffer, and then incubated with anti-HA beads. After washing, HA peptides was added to release the MMS19 protein complex. The purified MMS19 complex was separated by SDS-PAGE, visualized by silver staining, and processed for mass spectrometry (Liu et al. 2015). The whole gel were cut into four pieces. Excised gel fragments were washed with acetonitrile and then dried. After dried gel fragments were incubated with dithiothreitol solution at $56^{\circ} \mathrm{C}$, iodoacetamide solution was added. Gel fragments were washed and digested with trypsin (Promega) overnight. Extracted peptides were loaded into the column of C18 resin (ReproSil-Pur) and strong cation-exchange resin (Luna SCX 100A). LC-MS was done using LTQ Oribitrap MS (Thermo Fisher Scientific) and the MS data were analyzed using MaxQuant program following 
(Yang et al. 2015). A FDR ( False discovery rates ) of 0.01 for proteins and peptides and a minimum peptide length of 8 amino acids were required.

\subsection{Antibodies}

The used antibodies were as follows: rabbit anti-HA (Santa Cruz), mouse anti-MMS19 (Santa Cruz), rabbit anti-ANT2 (Cell signaling), mouse anti-GAPDH (Millipore), mouse anti-PCNA (Santa Cruz), rabbit anti-Tubulin (Santa Cruz), rabbit anti-VDAC (Cell signaling), and mouse anti-SMAC (Cell signaling).

\section{Results}

\subsection{MMS19 protein localizes to mitochondria}

Cytoplasmic/nuclear localization of MMS19 have been reported previously; and MMS19 is involved both in NER and transcription (Lombaerts et al. 1997). The previous studies demonstrates that oxidative damage is much higher in mitochondrial DNA than in nuclear DNA (Barja and Herrero 2000). As mitochondria DNA is constantly 
exposed to oxidative stress, MMS19 protein may be localized to mitochondria and participate in protecting mitochondria from oxidative damage. Western blot analysis was performed to detect the presence of MMS19 protein in the mitochondrial fractions isolated from HEK293 cells. Lack of detectable level of PCNA (nuclear protein marker) and Tubulin (cytoplasmic protein marker) in the lysis of mitochondrial fractions indicated that the mitochondrial fraction was free from nuclear and cytoplasmic contamination (Fig. 1A).

Alkali extraction assay was also performed to further demonstrate the mitochondrial location of MMS19 protein. When mitochondria samples were re-suspended to Alkali extraction, peripheral membrane proteins were obtained in the supernatant; integral membrane proteins were collected in the pellet (Fig. 1B). As expected, the outer membrane integral protein VDAC was primarily recovered in the pellet while the inter membrane space protein SMAC was largely recovered in the supernatant. MMS19 was distributed in both fractions, indicating that 
MMS19 is located not only in the integral membrane, but partially in the soluble fraction as well (Bannwarth et al. 2012).

\subsection{MMS19 deficiency leads to mtDNA CD and a defective mtDNA}

repair

Mitochondrial DNA mutations play a major role in human degenerative diseases and aging processes. The most frequently reported marker for mutations of the mtDNA in human is a 4,977 bp Common Deletion (CD) (Koch et al. 2001). A quantitative real-time polymerase chain reaction assay was established to detect the Common Deletion. As shown in Fig. 2A, MMS19-suppressed (siMMS19) and control (siControl) cells were treated with $1 \mathrm{mM} \mathrm{H} \mathrm{H}_{2}$ for 60 min and recover for 48 h. Our results showed MMS19 knockdown cells showed $>2$-fold higher increase of CD compared with control cells, suggesting that MMS19 protein is required to protect mtDNA from CD mutations coming from oxidative stress. Specifically, after 5,000 U/ml natural antioxidant catalase (an antioxidant agent) in company with $\mathrm{H}_{2} \mathrm{O}_{2}$ 
treatment the CD level in MMS19 knockdown U2OS cells were decreased in contrast to the level of controls. It means MMS19 deficiency could result in an elevated oxidative mtDNA damage that can be recovered by antioxidant catalase. As mentioned above, a long-range quantitative PCR amplification of $16.2 \mathrm{~kb}$ mtDNA was subsequently used for assessment of mtDNA repair efficiency (Yakes and Van Houten 1997). In this PCR reaction any unrepaired DNA will terminate chain elongation by DNA polymerase, thereby decreasing the efficiency of DNA amplification. The mtND1 PCR product (110 bp) was used to normalize differences in mtDNA input (Chi et al. 2012). The cells transfected with siControl and siMMS19 were treated with $1 \mathrm{mM}$ concentration of $\mathrm{H}_{2} \mathrm{O}_{2}$ to detect repair capacity in mitochondria in response to oxidative stress. As shown in Fig. 2B, both siControl and siMMS19-transfected U2OS cells showed a markedly decreased level of mtDNA PCR product at early time points after $\mathrm{H}_{2} \mathrm{O}_{2}$ treatment. In contrast to control cells, which showed the restoration of full-length mtDNA PCR product at $24 \mathrm{~h}$ post-treatment, a markedly decreased level of mtDNA PCR product was found in 
siMMS19-transfected U2OS cells even at $48 \mathrm{~h}$ post-treatment. These findings clearly illustrated that MMS19 is essential for the efficient repair of oxidative DNA damage in mitochondria. In contrast to increased mtDNA repair deficiency, no significant differences were observed in the copy number of nuclear $\beta$-globin gene either in knockdown of MMS19 U2OS cells or control after $\mathrm{H}_{2} \mathrm{O}_{2}$ treatment, suggesting that MMS19 is essential for the repair of oxidative stress in mitochondria but is dispensable for some of the nuclear genes such as $\beta$-globin.

\subsection{Interaction between MMS19 and ANT family protein SSBP1,} HSP7O

To find an unidentified function of MMS19 in mitochondria, Co-immunoprecipitation was used to identify the MMS19 protein complex from mitochondria. Human MMS19 cDNA fused with a HA tag at the $C$ terminus was stably expressed in HeLa S3 cells (Fig. 3A), and the intact mitochondria extract of which was used for sequential Co-immunoprecipitation with anti-HA beads (Fig. 3B). The MMS19 
complex was separated by polyacrylamide gel electrophoresis (SDS-PAGE) and visualized by silver staining (Fig. 3C). Mass spectrometry analysis (LC-MS/MS) was next performed to identify proteins interacted with MMS19 in mitochondria.

The mass spectrometry analysis of the MMS19 complex detected ANT1, ANT2, ANT3, SSBP1 and HSP70 proteins (Supplementary Table 1). ANT is an ADP/ATP translocase, function of which is to catalyze mitochondrial ADP/ATP exchange (Cho et al. 2017). SSBP1 is a mitochondrial protein involved in mitochondrial DNA replication. While HSP70 serves as molecular chaperone in assisting protein transport. To further validate the potential partners that interacts with MMS19 in mitochondria, co-immunoprecipitation (Co-IP) assay was used to identify protein-protein interactions. For this task, whole cell lysates from 293F human kidney cells expressing Flag-HA-ANT1, Flag-HA-ANT2 and Flag-HA-ANT3 was prepared. When cell lysates were incubated with anti-HA agarose beads, endogenous MMS19 was detected by anti-MMS19 antibody, and the tagged proteins were detected by HA 
antibody, demonstrating the physical interaction between ANT family and MMS19 (Fig. 3D). Likewise, SSBP1 and HSP70 were also detected in protein complex of MMS19 (Fig. 3E).

\subsection{ANT2 plays a role in mtDNA repair}

Subsequently, we explored whether ANT2 was involved in oxidative mtDNA damage repair. U2OS cells were transfected with siControl and siANT2 . As mentioned above, long-range mtDNA PCR was used to quantify the capacity for mtDNA oxidative damage repair. After exposure to $1 \mathrm{mM} \mathrm{H}_{2} \mathrm{O}_{2}$ for $1 \mathrm{~h}$, both control and ANT2 knockdown U2OS cells had a markedly decreased level of mtDNA PCR product at early time-points after $\mathrm{H}_{2} \mathrm{O}_{2}$ treatment. However, control cells showed the restoration of full-length mtDNA PCR product at $24 \mathrm{~h}$, whereas cells with knockdown of ANT2 gene expression showed a very low-level of PCR product, even at $48 \mathrm{~h}$ post-treatment (Fig. 4). Similar as MMS19, ANT2 deficiency also results in remarkably attenuating mtDNA oxidative 
damage repair compared to control cells, but it is dispensable for some nuclear gene such as $\beta$-globin.

\section{Discussion}

Mitochondria are essential cellular organelles in every single living eukaryote, which provide energy in the form of ATP and important metabolic intermediates to a number of cellular functions including lipid biogenesis. In addition, mitochondria are important for other key processes including calcium homeostasis, iron-sulfur cluster biogenesis, and heme production (Van Houten et al. 2016). Mitochondrial DNA is constantly exposed to oxidative stress. Most intracellular reactive oxygen species (ROS) are produced in mitochondria; mtDNA is more susceptible than nuclear DNA to oxidative damage. ROS can generate a large number of DNA lesions, including oxidized DNA bases, abasic sites, and single- and double-strand breaks. Many of these ROS-induced DNA lesions show mutagenic or cytotoxic effects due to mispair of bases, which may give rise to mutations upon DNA replication (Gredilla et al. 
2010). The steady-state levels of oxidatively induced mtDNA lesions can be several fold higher than nuclear DNA (Hamilton et al. 2001). MMS19 has been reported as an upstream regulator of TFIIH activity, which is indispensable for both NER and RNA polymerase II transcription (Kou et al. 2008).

Early studies demonstrate that MMS19 plays specific physiological role based on its sub-cellular distributions. In nuclear, human MMS19 interacts with two components of TFIIH: XPB and the Rad3 homolog XPD, so exerting its function in DNA repair and transcription. In cytoplasm, MMS19 interacts with XPD forming MMXD complex independently of TFIIH and is proposed to play a role in mitotic spindle formation and chromosome segregation, an abnormality of which could contribute to the pathogenesis in some cases of xeroderma pigmentosum (XP) and XP combined with Cockayne syndrome. However, whether or not MMS19 protein locations and functions in mitochondria remains unclear. Western blotting analysis of the lysis of cellular fractions showed the presence of the MMS19 protein in the mitochondrial fraction, which 
demonstrated that MMS19 protein was co-localized with mitochondria. Moreover, alkali extraction experiments demonstrated that MMS19 was present in both the membrane-containing pellet and soluble fraction of mitochondria.

The stability of mtDNA is constantly challenged by the endogenous production of mitochondrial ROS (mtROS), which are generated during normal electron flux through the mitochondrial electron transport. Unlike nuclear DNA, mtDNA is located in the proximity of mtROS generation-sites which are located within complex I and III of the electron transport chain (Muller et al. 2004). In the study, we observed that MMS19 knockdown led to a significantly increased CD level, and also a substantially lower capacity for repairing the mtDNA oxidative damage. Although a molecular explanation of how MMS19 affects so many different processes has remained elusive, this study indicates that MMS19 deficiency is likely to result in defective repair of oxidative damage in the mitochondrial DNA, leading to a higher mutation rate of mtDNA. MMS19 deficiency selectively affects the oxidative DNA damage 
repair capacity of mtDNA but not nuclear genes such as $\beta$-globin, suggesting that MMS19 is a critical factor for repair machinery of oxidative DNA damage operating in mitochondria.

We next searched for other patterns that may corroborate with MMS19 protein in the repair of mitochondrial oxidative DNA damages by Co-immunoprecipitation together with liquid chromatography-mass spectrometry analysis on mitochondrial fraction. Results showed that MMS19 interacted with ANT family, SSBP1 and HSP70, respectively, which was further validated by Co-IP analysis. ANTs play an essential role for energy metabolism of eukaryotic cell by transporting ADP and ATP through mitochondrial inner membrane (Cho et al. 2015). We observed that MMS19 physically interacted with ANT1, ANT2 and ANT3 in mitochondria. Similar to its interacting partner, a significantly decreased capacity for repairing mitochondrial oxidative DNA damages was also observed when ANT2 expression in mitochondria was suppressed. SSBP1 (also known as mtSSB) is distinct from nuclear SSB, exists in eukaryotic mitochondria, and plays an important role in mtDNA replication, 
recombination, and repair by binding to single-stranded mtDNA (Farr et al. 1999; Jiang et al. 2016). The interaction between MMS19 and SSBP1 suggested MMS19 indirectly involved in oxidative DNA damage repair capacity of mtDNA through SSBP1. Mass spectrometry analysis also showed that MMS19 physically interacted with HSP70, suggesting a potential mechanism in which MMS19 enters mitochondria by interacting with molecular chaperone HSP70. Taken together, our findings uncover strong evidence that MMS19 is involved in mtDNA repair for oxidative damage and plays an essential role in maintaining mitochondrial genome DNA stability.

\section{Acknowledgements}

This work was supported by the National Natural Science Foundation of China [grant No. 31570815] ; and the National Basic Research Program of China [973 program; grant No. 2015CB910600].

\section{References}


Bannwarth, S., Figueroa, A., Fragaki, K., Destroismaisons, L., Lacas-Gervais, S., Lespinasse, F., Vandenbos, F., Pradelli, L.A., Ricci, J.E., Rotig, A., Michiels, J.F., Vande Velde, C., and Paquis-Flucklinger, V. 2012. The human MSH5 (MutSHomolog 5) protein localizes to mitochondria and protects the mitochondrial genome from oxidative damage. Mitochondrion 12(6): 654-665. doi: 10.1016/j.mito.2012.07.111.

Barja, G., and Herrero, A. 2000. Oxidative damage to mitochondrial DNA is inversely related to maximum life span in the heart and brain of mammals. FASEB journal : official publication of the Federation of American Societies for Experimental Biology 14(2): 312-318.

Bohr, V.A. 2002. Repair of oxidative DNA damage in nuclear and mitochondrial DNA, and some changes with aging in mammalian cells. Free radical biology \& medicine 32(9): 804-812.

Chi, Z., Nie, L., Peng, Z., Yang, Q., Yang, K., Tao, J., Mi, Y., Fang, X., Balajee, A.S., and Zhao, Y. 2012. RecQL4 cytoplasmic localization: implications in mitochondrial DNA oxidative damage repair. Int J Biochem Cell Biol 44(11): 1942-1951. doi: 10.1016/j.biocel.2012.07.016.

Cho, J., Seo, J., Lim, C.H., Yang, L., Shiratsuchi, T., Lee, M.H., Chowdhury, R.R., Kasahara, H., Kim, J.S., Oh, S.P., Lee, Y.J., and Terada, N. 2015. Mitochondrial ATP transporter Ant2 depletion impairs erythropoiesis and B lymphopoiesis. Cell death and differentiation 22(9): 1437-1450. doi: 10.1038/cdd.2014.230.

Cho, J., Zhang, Y., Park, S.Y., Joseph, A.M., Han, C., Park, H.J., Kalavalapalli, S., Chun, S.K., Morgan, D., Kim, J.S., Someya, S., Mathews, C.E., Lee, Y.J., Wohlgemuth, S.E., Sunny, N.E., Lee, H.Y., Choi, C.S., Shiratsuchi, T., Oh, S.P., and Terada, N. 2017. 
Mitochondrial ATP transporter depletion protects mice against liver steatosis and insulin resistance. Nat Commun 8: 14477. doi: 10.1038/ncomms14477.

Farr, C.L., Wang, Y., and Kaguni, L.S. 1999. Functional interactions of mitochondrial DNA polymerase and single-stranded DNA-binding protein. Template-primer DNA binding and initiation and elongation of DNA strand synthesis. The Journal of biological chemistry 274(21): 14779-14785.

Gari, K., Leon Ortiz, A.M., Borel, V., Flynn, H., Skehel, J.M., and Boulton, S.J. 2012. MMS19 links cytoplasmic iron-sulfur cluster assembly to DNA metabolism. Science 337(6091): 243-245. doi: 10.1126/science.1219664.

Graham, J.M. 2001. Isolation of mitochondria from tissues and cells by differential centrifugation. Current protocols in cell biology / editorial board, Juan S. Bonifacino ... [et al.] Chapter 3: Unit 3.3. doi: 10.1002/0471143030.cb0303s04.

Gredilla, R., Bohr, V.A., and Stevnsner, T. 2010. Mitochondrial DNA repair and association with aging--an update. Experimental gerontology 45(7-8): 478-488. doi: 10.1016/j.exger.2010.01.017.

Hamilton, M.L., Guo, Z., Fuller, C.D., Van Remmen, H., Ward, W.F., Austad, S.N., Troyer, D.A., Thompson, I., and Richardson, A. 2001. A reliable assessment of 8-oxo-2-deoxyguanosine levels in nuclear and mitochondrial DNA using the sodium iodide method to isolate DNA. Nucleic acids research 29(10): 2117-2126.

Ito, S., Tan, L.J., Andoh, D., Narita, T., Seki, M., Hirano, Y., Narita, K., Kuraoka, I., Hiraoka, Y., and Tanaka, K. 2010. MMXD, a TFIIH-independent XPD-MMS19 protein complex involved in chromosome segregation. Molecular cell 39(4): 632-640. doi: 10.1016/j.molcel.2010.07.029. 
Jiang, H.L., Sun, H.F., Gao, S.P., Li, L.D., Huang, S., Hu, X., Liu, S., Wu, J., Shao, Z.M., and Jin, W. 2016. SSBP1 Suppresses TGFbeta-Driven Epithelial-to-Mesenchymal Transition and Metastasis in Triple-Negative Breast Cancer by Regulating Mitochondrial Retrograde Signaling. Cancer research 76(4): 952-964. doi: 10.1158/0008-5472.can-15-1630.

Kamenisch, Y., Fousteri, M., Knoch, J., von Thaler, A.K., Fehrenbacher, B., Kato, H., Becker, T., Dolle, M.E., Kuiper, R., Majora, M., Schaller, M., van der Horst, G.T., van Steeg, H., Rocken, M., Rapaport, D., Krutmann, J., Mullenders, L.H., and Berneburg, M. 2010. Proteins of nucleotide and base excision repair pathways interact in mitochondria to protect from loss of subcutaneous fat, a hallmark of aging. The Journal of experimental medicine 207(2): 379-390. doi: 10.1084/jem.20091834.

Klaunig, J.E., Wang, Z., Pu, X., and Zhou, S. 2011. Oxidative stress and oxidative damage in chemical carcinogenesis. Toxicology and applied pharmacology 254(2): 86-99. doi: 10.1016/j.taap.2009.11.028.

Koch, H., Wittern, K.P., and Bergemann, J. 2001. In human keratinocytes the Common Deletion reflects donor variabilities rather than chronologic aging and can be induced by ultraviolet $A$ irradiation. The Journal of investigative dermatology 117(4): 892-897. doi: 10.1046/j.0022-202x.2001.01513.x.

Kou, H., Zhou, Y., Gorospe, R.M., and Wang, Z. 2008. Mms19 protein functions in nucleotide excision repair by sustaining an adequate cellular concentration of the TFIIH component Rad3. Proceedings of the National Academy of Sciences of the United States of America 105(41): 15714-15719. doi: 10.1073/pnas.0710736105. 
Liu, J., Fang, H., Chi, Z., Wu, Z., Wei, D., Mo, D., Niu, K., Balajee, A.S., Hei, T.K., Nie, L., and Zhao, Y. 2015. XPD localizes in mitochondria and protects the mitochondrial genome from oxidative DNA damage. Nucleic acids research 43(11): 5476-5488. doi: $10.1093 /$ nar/gkv472.

Lombaerts, M., Tijsterman, M., Verhage, R.A., and Brouwer, J. 1997. Saccharomyces cerevisiae mms19 mutants are deficient in transcription-coupled and global nucleotide excision repair. Nucleic acids research 25(20): 3974-3979.

Maynard, S., Schurman, S.H., Harboe, C., de Souza-Pinto, N.C., and Bohr, V.A. 2009. Base excision repair of oxidative DNA damage and association with cancer and aging. Carcinogenesis 30(1): 2-10. doi: 10.1093/carcin/bgn250.

Melis, J.P., van Steeg, H., and Luijten, M. 2013. Oxidative DNA damage and nucleotide excision repair. Antioxidants \& redox signaling 18(18): 2409-2419. doi: 10.1089/ars.2012.5036.

Muller, F.L., Liu, Y., and Van Remmen, H. 2004. Complex III releases superoxide to both sides of the inner mitochondrial membrane. The Journal of biological chemistry 279(47): 49064-49073. doi: 10.1074/jbc.M407715200.

Queimado, L., Rao, M., Schultz, R.A., Koonin, E.V., Aravind, L., Nardo, T., Stefanini, M., and Friedberg, E.C. 2001. Cloning the human and mouse MMS19 genes and functional complementation of a yeast mms19 deletion mutant. Nucleic acids research 29(9): 1884-1891.

Seroz, T., Winkler, G.S., Auriol, J., Verhage, R.A., Vermeulen, W., Smit, B., Brouwer, J., Eker, A.P., Weeda, G., Egly, J.M., and Hoeijmakers, J.H. 2000. Cloning of a human homolog of the yeast nucleotide excision repair gene MMS19 and interaction 
with transcription repair factor TFIIH via the XPB and XPD helicases. Nucleic acids research 28(22): 4506-4513.

Stehling, O., Vashisht, A.A., Mascarenhas, J., Jonsson, Z.O., Sharma, T., Netz, D.J., Pierik, A.J., Wohlschlegel, J.A., and Lill, R. 2012. MMS19 assembles iron-sulfur proteins required for DNA metabolism and genomic integrity. Science 337(6091): 195-199. doi: 10.1126/science.1219723.

Van Houten, B., Hunter, S.E., and Meyer, J.N. 2016. Mitochondrial DNA damage induced autophagy, cell death, and disease. Frontiers in bioscience (Landmark edition) 21: 42-54.

Yakes, F.M., and Van Houten, B. 1997. Mitochondrial DNA damage is more extensive and persists longer than nuclear DNA damage in human cells following oxidative stress. Proceedings of the National Academy of Sciences of the United States of America 94(2): 514-519.

Yang, G., Xu, Z., Lu, W., Li, X., Sun, C., Guo, J., Xue, P., and Guan, F. 2015. Quantitative Analysis of Differential Proteome Expression in Bladder Cancer vs. Normal Bladder Cells Using SILAC Method. PloS one 10(7): e0134727. doi: 10.1371/journal.pone.0134727.

\section{FIGURE LEGENDS}

Fig. 1 : The localization of MMS19 protein in mitochondria by western blotting coupled with alkali extraction method on isolated mitochondrial fraction. (A) Endogenous MMS19 from both 
mitochondrial and nuclear fractions of HEK293 cells was determined by western blotting. Presence of MMS19 protein in mitochondrial fraction was detected. VDAC was used as a mitochondrial marker. PCNA was used as a nuclear marker, and Tubulin as a marker for contamination by cytosol. (B) Mitochondria from HEK293 cells were subjected to alkali extraction. VDAC and SMAC were used to identify behaviors of well defined mitochondrial proteins that were integral membrane protein and soluble, respectively. Both the integral membrane protein and soluble protein fraction were isolated and checked by western blotting.

' $M$ ' indicates extracted mitochondria sample without other treatment.

The data demonstrated the MMS19 localization in both the inner mitochondrial membrane and mitochondrial inner matrix compartment.

Fig. 2 : MMS19 protein is critical in MMS19-regulated mtDNA repair. (A) The relative quantities of $C D$ was measured by real-time quantitative PCR in MMS19 knockdown and control U2OS cells at $48 \mathrm{~h}$ after $1 \mathrm{mM} \mathrm{H}_{2} \mathrm{O}_{2}$ treatment in the presence or absence of $5,000 \mathrm{U} / \mathrm{ml}$ of 
Catalase. The relative levels of CD were assessed using Bio-Rad CFX Manager v3.0. Samples were collected at $0 \mathrm{~h}$ (Con) and $48 \mathrm{~h}$ recovery with or without catalase $\left(\mathrm{H}_{2} \mathrm{O}_{2}\right.$ or $\mathrm{H}_{2} \mathrm{O}_{2}+$ catalase) post treatment. (B) Long-range QPCR results of full-length mitochondrial DNA (mt-FL) in siControl and siMMS19 U2OS cells at 0,6, 12, 24, $48 \mathrm{~h}$ after $1 \mathrm{mM} \mathrm{H} \mathrm{O}_{2}$ treatment for $1 \mathrm{~h}$. The $110 \mathrm{bp} \mathrm{mtND1} \mathrm{PCR} \mathrm{product} \mathrm{was} \mathrm{used} \mathrm{as} \mathrm{a} \mathrm{control}$ to normalize the input of the mtDNA template amount in each sample. Nuclear $\beta$-globin gene was used as the repair efficiency marker for nuclear DNA damage.

\section{Fig. 3 : Characterization of MMS19 protein complex in} mitochondria. (A) Establishment of stable HeLa S3 cell lines overexpressing HA-MMS19. (B) Experimental procedure for purification of MMS19 protein complex in mitochondria. (C) Silver staining of MMS19 protein complexes purified from mitochondrial extracts. As a control, a mock purification was performed with mitochondrial extracts from non-transfected HeLa S3 cells. Purified polypeptides were 
processed for Liquid chromatography-tandem mass spectrometry. (D)

Endogenous MMS19 was observed in the ANT pull-down complex. (E)

Exogenous MMS19 was observed in the SSBP1 pull-down complex.

Exogenous HSP70 was observed in the MMS19 pull-down complex.

Fig. 4 : Result of long-range QPCR in siControl and siANT2 U2OS

cells. Long-range QPCR results of full-length mitochondrial DNA (mt-FL)

at $0,6,12,24,48 \mathrm{~h}$ after treatment with $1 \mathrm{mM} \mathrm{H}_{2} \mathrm{O}_{2}$ for $1 \mathrm{~h}$. Equal amount

of mtDNA template DNA in each sample was normalized by mtND1.

Supplementary Table $\mathbf{1}$. The data of proteins interacted with MMS19 in mitochondria by using Co-immunoprecipitation-LC-MS/MS. 
Figure1

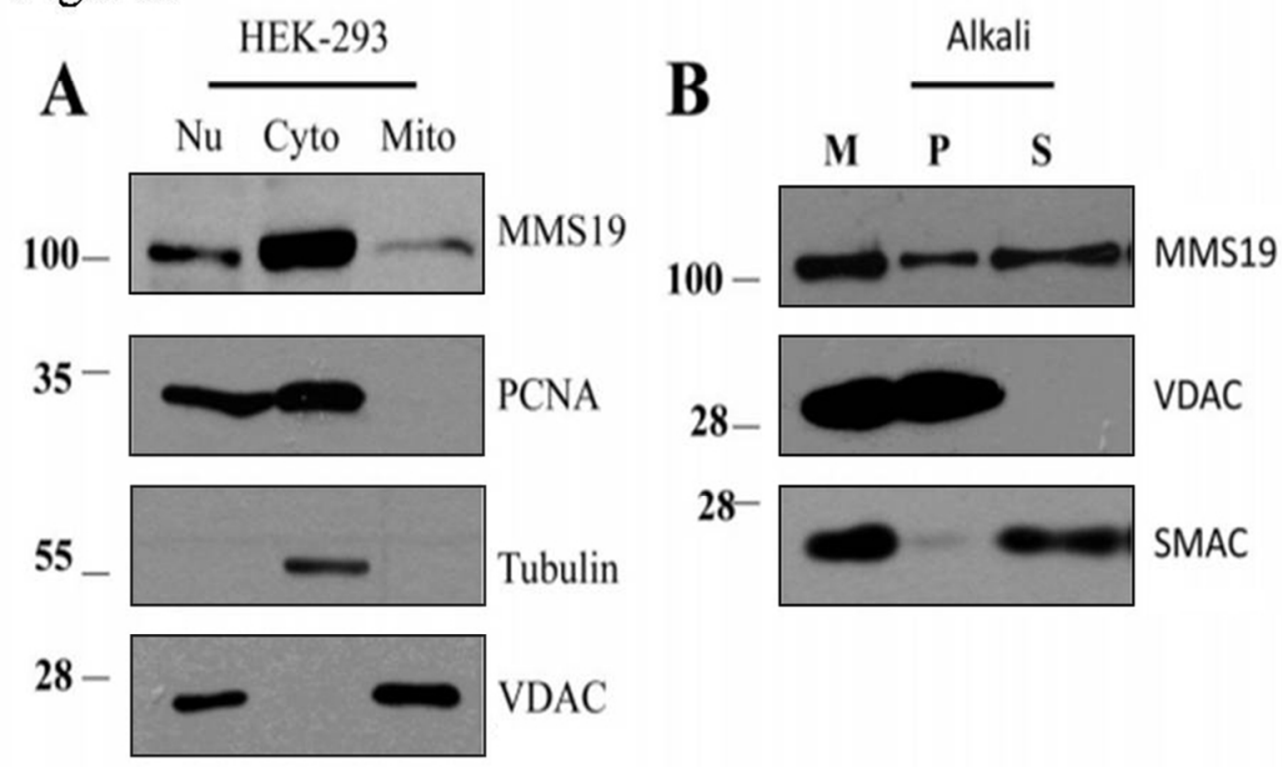

Fig. 1 : The localization of MMS19 protein in mitochondria by western blotting coupled with alkali extraction method on isolated mitochondrial fraction.

$90 \times 57 \mathrm{~mm}(300 \times 300 \mathrm{DPI})$ 
Figure2

A

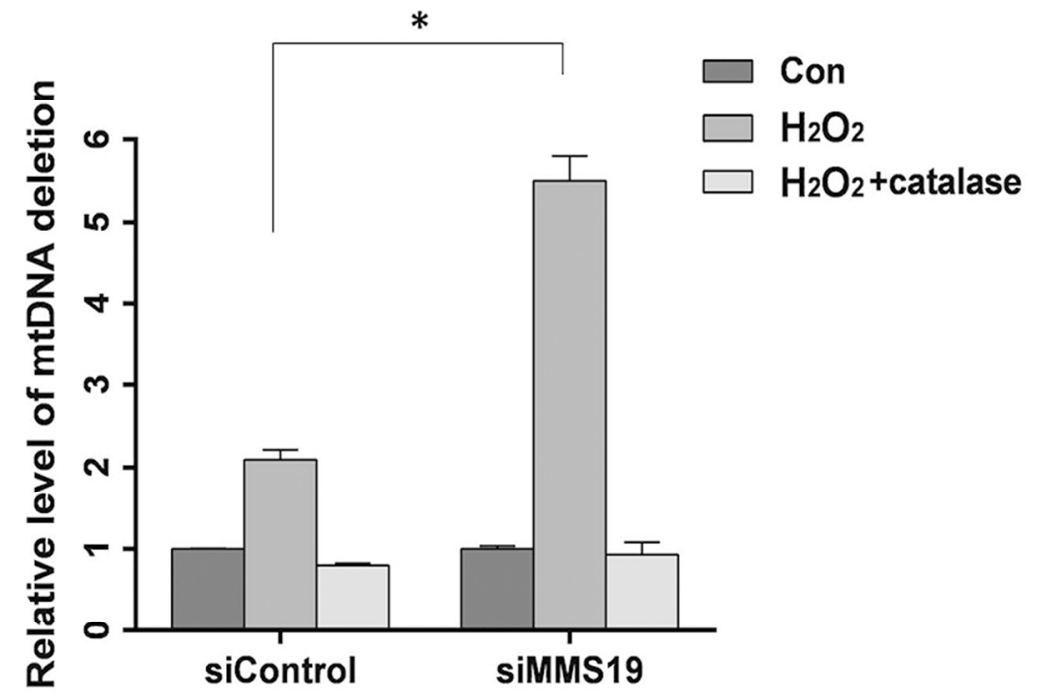

B

\begin{tabular}{|c|c|c|c|c|c|c|c|c|c|c|c|c|}
\hline \multicolumn{6}{|c|}{ U2OS-siControl } & \multicolumn{6}{|c|}{ siMMS19 } & \multirow[b]{2}{*}{$1 \mathrm{mM} \mathrm{H}_{2} \mathrm{O}_{2}$} \\
\hline$=$ & + & + & + & + & + & - & + & + & + & + & + & \\
\hline 0 & 0 & 6 & 12 & 24 & 48 & 0 & 0 & 6 & 12 & 24 & 48 & Recover(h) \\
\hline- & & 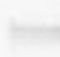 & 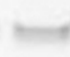 & 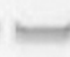 & - & 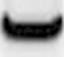 & & & $\mathrm{k}$ & $=$ & $=$ & hmt-FL \\
\hline
\end{tabular}

13.5kb $----\infty-\infty-\infty-$ B-globin

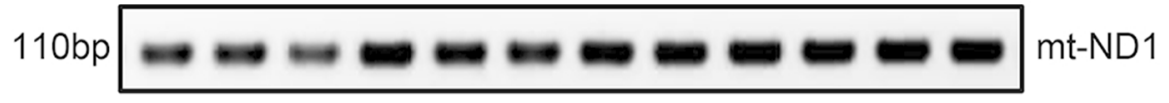

Fig. 2 : MMS19 protein is critical in MMS19-regulated mtDNA repair.

$$
90 \times 109 \mathrm{~mm}(300 \times 300 \text { DPI })
$$




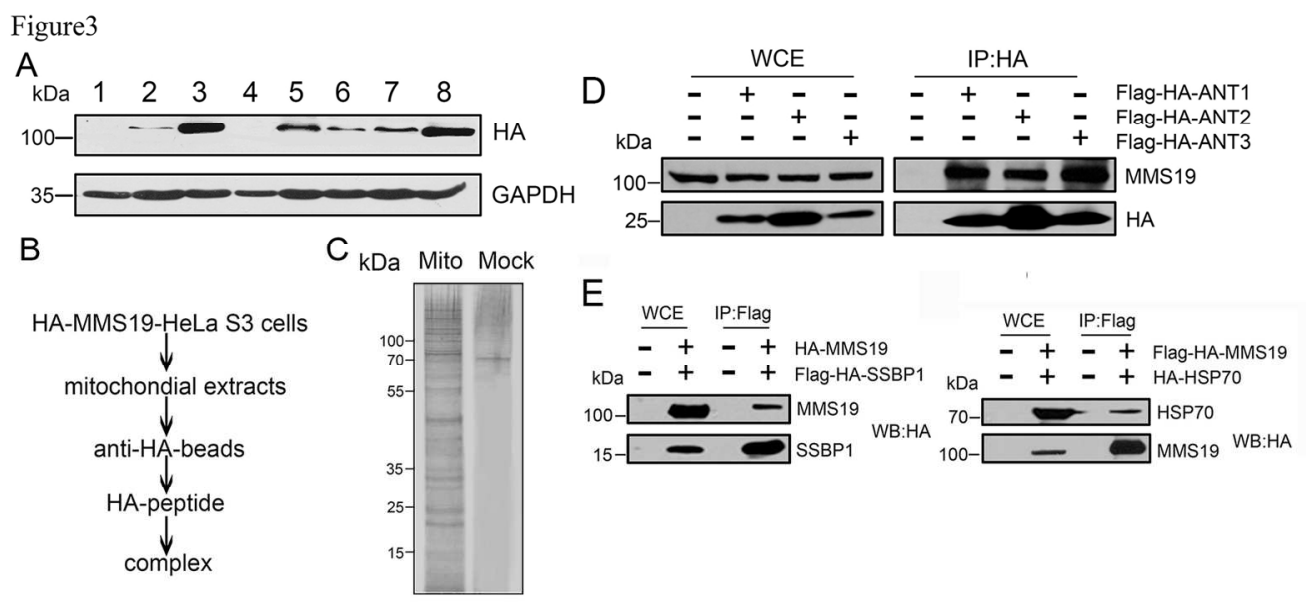

Fig. 3 : Characterization of MMS19 protein complex in mitochondria.

$160 \times 74 \mathrm{~mm}(300 \times 300 \mathrm{DPI})$ 
Figure4

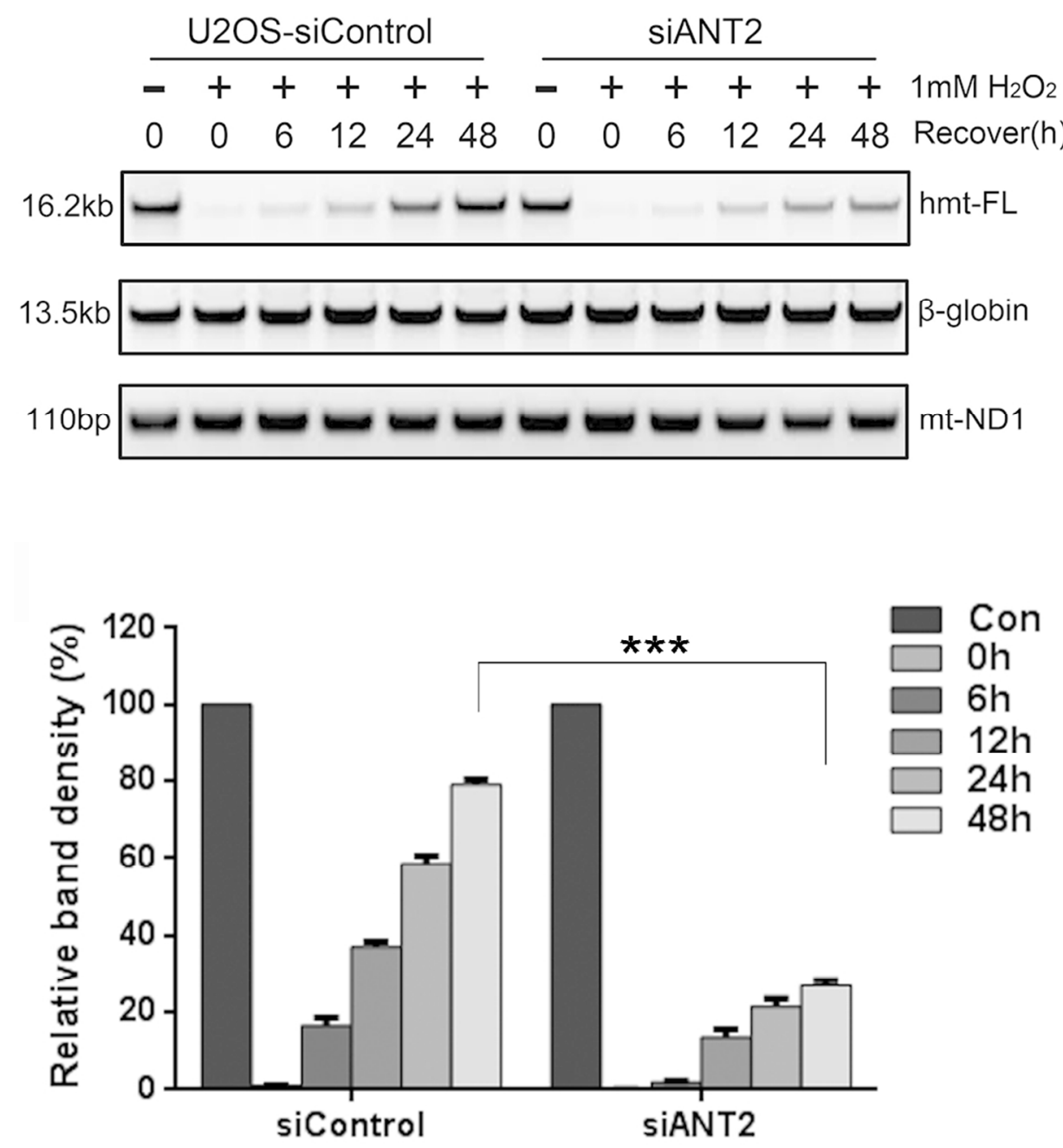

Fig. 4 : Result of long-range QPCR in siControl and siANT2 U2OS cells. $90 \times 109 \mathrm{~mm}(300 \times 300 \mathrm{DPI})$ 


\begin{tabular}{|c|c|c|c|c|c|c|}
\hline Accession & Description & $\Sigma$ Coverage & $\Sigma \#$ Proteins & $\begin{array}{c}\Sigma \# \text { Unique } \\
\text { Peptides }\end{array}$ & $\Sigma \#$ Peptides & $\Sigma \#$ PSMs \\
\hline \multirow[t]{10}{*}{ P05141 } & $\begin{array}{l}\text { ADP/ATP translocase } 2 \text { OS=Homo sapiens } \\
\text { GN=SLC25A5 PE=1 SV=7 - } \\
\text { [ADT2_HUMAN] }\end{array}$ & 28.19 & 3 & 4 & 8 & 9 \\
\hline & Sequence & \# PSMs & \# Proteins & $\begin{array}{l}\text { \# Protein } \\
\text { Groups }\end{array}$ & $\begin{array}{c}\text { Protein Group } \\
\text { Accessions }\end{array}$ & Modifications \\
\hline & DFLAGGVAAAISK & 1 & 1 & 1 & P05141 & \\
\hline & QIFLGGVDKR & 1 & 1 & 1 & P05141 & \\
\hline & GIIDCVVR & 1 & 2 & 1 & P05141 & $\begin{array}{c}\text { C5(Carbamido } \\
\text { methyl) }\end{array}$ \\
\hline & YFPTQALNFAFKDK & 1 & 5 & 2 & $\begin{array}{c}\mathrm{P} 12236 ; \mathrm{P} 0514 \\
1\end{array}$ & \\
\hline & YFPTQALNFAFK & 1 & 5 & 2 & $\begin{array}{c}\text { P12236;P0514 } \\
1 \\
\end{array}$ & \\
\hline & AAYFGIYDTAK & 1 & 1 & 1 & P05141 & \\
\hline & VKLLLQVQHASK & 1 & 4 & 2 & $\begin{array}{c}\text { P12236;P0514 } \\
1\end{array}$ & \\
\hline & GMGGAFVLVLYDEIKK & 2 & 3 & 2 & $\begin{array}{c}\text { P12236;P0514 } \\
1 \\
\end{array}$ & M2(Oxidation) \\
\hline \multirow[t]{7}{*}{ Q04837 } & $\begin{array}{l}\text { Single-stranded DNA-binding protein, } \\
\text { mitochondrial OS=Homo sapiens } \\
\text { GN=SSBP1 PE=1 SV=1 - } \\
\text { [SSBP_HUMAN] }\end{array}$ & 39.86 & 3 & 5 & 5 & 7 \\
\hline & Sequence & \# PSMs & \# Proteins & $\begin{array}{l}\text { \# Protein } \\
\text { Groups }\end{array}$ & $\begin{array}{c}\text { Protein Group } \\
\text { Accessions }\end{array}$ & Modifications \\
\hline & \begin{tabular}{|l} 
QATTIIADNIIFLSDQTK \\
\end{tabular} & 3 & 1 & 1 & Q04837 & \\
\hline & SGDSEVYQLGDVSQK & 1 & 3 & 1 & Q04837 & \\
\hline & VGQDPVLR & 1 & 3 & 1 & Q04837 & \\
\hline & QATTIIADNIIFLSDQTKEKE & 1 & 1 & 1 & Q04837 & \\
\hline & NPVTIFSLATNEMWR & 1 & 3 & 1 & Q04837 & $\begin{array}{c}\text { M13(Oxidatio } \\
\text { n) }\end{array}$ \\
\hline \multirow[t]{7}{*}{ P12236 } & $\begin{array}{l}\text { ADP/ATP translocase } 3 \text { OS=Homo sapiens } \\
\text { GN=SLC25A6 PE }=1 \mathrm{SV}=4 \text { - } \\
\text { [ADT3_HUMAN] }\end{array}$ & 18.46 & 3 & 1 & 5 & 6 \\
\hline & Sequence & \# PSMs & \# Proteins & $\begin{array}{l}\text { \# Protein } \\
\text { Groups }\end{array}$ & $\begin{array}{c}\text { Protein Group } \\
\text { Accessions }\end{array}$ & Modifications \\
\hline & DFLAGGIAAAISK & 1 & 2 & 1 & $\mathrm{P} 12236$ & \\
\hline & YFPTQALNFAFKDK & 1 & 5 & 2 & $\begin{array}{c}\text { P12236;P0514 } \\
1 \\
\end{array}$ & \\
\hline & YFPTQALNFAFK & 1 & 5 & 2 & $\begin{array}{c}\text { P12236;P0514 } \\
1 \\
\end{array}$ & \\
\hline & VKLLLQVQHASK & 1 & 4 & 2 & $\begin{array}{c}\text { P12236;P0514 } \\
1 \\
\end{array}$ & \\
\hline & GMGGAFVLVLYDELKK & 2 & 3 & 2 & $\begin{array}{c}\text { P12236;P0514 } \\
1 \\
\end{array}$ & M2(Oxidation) \\
\hline \multirow[t]{3}{*}{ H0Y5S7 } & $\begin{array}{l}\text { Heat shock protein HSP 70-beta } \\
\text { (Fragment) OS=Homo sapiens } \\
\text { GN=HSP70AB1 PE=4 SV=1 - } \\
{[\text { H0Y5S7_HUMAN] }}\end{array}$ & 9.86 & 11 & 1 & 1 & 3 \\
\hline & Sequence & \# PSMs & \# Proteins & $\begin{array}{l}\text { \# Protein } \\
\text { Groups }\end{array}$ & $\begin{array}{c}\text { Protein Group } \\
\text { Accessions }\end{array}$ & Modifications \\
\hline & GVVDSEDLPLNISR & 3 & 11 & 1 & H0Y5S7 & \\
\hline
\end{tabular}

